\title{
Community reductions in youth smoking after raising the minimum tobacco sales age to 21
}

\author{
Shari Kessel Schneider, ${ }^{1}$ Stephen L Buka ${ }_{1}{ }^{2}$ Kim Dash, ${ }^{1}$ Jonathan P Winickoff, ${ }^{3}$ \\ Lydia O'Donnell ${ }^{1}$
}

${ }^{1}$ Education Development Center, Inc, Waltham, Massachusetts, USA 2Department of Epidemiology, Brown University, Providence, Rhode Island, USA

${ }^{3}$ Harvard Medical School, Boston, Massachusetts, USA

\section{Correspondence to}

Shari Kessel Schneider Education Development Center (EDC), Inc, 43 Foundry Ave, Waltham, MA 02453, USA; skschneider@edc.org

Received 18 December 2014 Accepted 12 May 2015 Published Online First 12 June 2015
CrossMark

To cite: Kessel Schneider $\mathrm{S}$, Buka SL, Dash K, et al. Tob Control 2016:25:355-359.

\begin{abstract}
Objective Raising the tobacco sales age to 21 has gained support as a promising strategy to reduce youth cigarette access, but there is little direct evidence of its impact on adolescent smoking. Using regional youth survey data, we compared youth smoking trends in Needham, Massachusetts - which raised the minimum purchase age in 2005-with those of 16 surrounding communities.

Methods The MetroWest Adolescent Health Survey is a biennial census survey of high school youth in communities west of Boston; over 16000 students participated at each of four time points from 2006 to 2012. Using these pooled cross-section data, we used generalised estimating equation models to compare trends in current cigarette smoking and cigarette purchases in Needham relative to 16 comparison communities without similar ordinances. To determine whether trends were specific to tobacco, we also examined trends in youth alcohol use over the same time period.
\end{abstract}

Results From 2006 to 2010, the decrease in 30-day smoking in Needham (from 13\% to $7 \%$ ) was significantly greater than in the comparison communities (from 15\% to $12 \% ; p<.001)$. This larger decline was consistent for both genders, Caucasian and non-Caucasian youth, and grades 10, 11 and 12. Cigarette purchases among current smokers also declined significantly more in Needham than in the comparison communities during this time. In contrast, there were no comparable differences for current alcohol use.

Conclusions Our results suggest that raising the minimum sales age to 21 for tobacco contributes to a greater decline in youth smoking relative to communities that did not pass this ordinance. These findings support local community-level action to raise the tobacco sales age to 21 .

\section{INTRODUCTION}

Raising the legal age of tobacco sales to 21 to reduce youth smoking has gained increasing support among prevention advocates ${ }^{1}$ who are working to reduce youth smoking initiation as a primary means of preventing addiction later in life. Nearly 1 in 10 high school youth experiment with cigarettes before age 13 , and $4 \%$ have smoked regularly. ${ }^{2}$ These youth who initiate smoking in adolescence are at greater risk of becoming addicted to tobacco as adults. ${ }^{34}$ Conversely, research shows that the majority of adults who are addicted to cigarettes began smoking daily before age $18 .^{4}$

In addition, many people who purchase cigarettes for minors are under 21 themselves. ${ }^{5}$ This suggests that prohibiting young adults under 21 from purchasing cigarettes would reduce the number of legal buyers in adolescents' social circles, thereby disrupting the supply of cigarettes to adolescents. Given that youth attitudes towards smoking, such as perceived risk and disapproval of smoking, have levelled off or lessened since $2007,{ }^{6}$ reducing access to cigarettes is an important prevention strategy.

A recent report by the Institute of Medicine suggests that raising the minimum age of legal access to tobacco to 21 would result in a $12 \%$ decrease in the prevalence of tobacco use among today's teenagers once they become adults. ${ }^{7}$ Another simulation of the impact of raising the legal smoking age to 21 in the USA suggests that adolescent smoking would be reduced by more than half in 7 years. ${ }^{8}$ There is broad public support for this effort, with $70 \%$ of adults in support of raising the minimum sales age to 21, including a majority of adults in all demographic and smoking status categories. ${ }^{9}$ Despite these promising projections, there is little direct evidence that raising the minimum purchase age for tobacco would lead to a decline in youth smoking.

In April of 2005, Needham, Massachusetts became the first town in the USA to raise the minimum tobacco sales age to 21; it was not adopted elsewhere in the USA until 2012 (DJ Wilson, Director, Massachusetts Municipal Association Tobacco Control Technical Assistance Program, personal communication, 7 November 2014.). In this paper, we use data from the MetroWest Adolescent Health Survey (MWAHS) to compare youth smoking trends from 2006 to 2012 in Needham with 16 surrounding communities that did not pass this ordinance. To the best of our knowledge, this is the first study to examine trends in the actual prevalence of smoking associated with raising the minimum sales age. We examined: (1) whether smoking declined more in Needham than in the nearby communities; and (2) whether the effect was specific to tobacco or if similar patterns were also found for alcohol.

\section{METHODS}

The MWAHS is a school-based census of youth in 25 communities in the Boston metropolitan area served by the MetroWest Health Foundation, having the primary goal of informing local prevention efforts. It has been administered biennially since fall, 2006 to students in grades 9-12. Of the 26 public high schools in the region served by the foundation, 18 began the survey in 2006. Of these, 17 high schools participated in all four surveys (2006, 2008, 2010 and 2012) and are included in this analysis. Student participation rates ranged from $88.8 \%$ to $89.6 \%$ over the four surveys, and the number of participants ranged from 16385 to 
17089 each year. Student gender and grade distributions were similar across all years.

\section{Measures}

The MWAHS instrument is a classroom-administered anonymous survey that incorporates items from the Center for Disease Control and Prevention's Youth Risk Behavior Survey. ${ }^{10}$ We examined two tobacco outcome measures: (1) current (30-day) cigarette smoking (any vs none) using the question "During the past 30 days, on how many days did you smoke cigarettes", and (2) current (30-day) purchase of cigarettes in a store (any vs none), using the question "During the past 30 days, how did you usually get your own cigarettes?" with seven response categories: did not try to get cigarettes/bought them in a store/gave someone else money to buy them for me/borrowed or bummed them/a person 18 or older gave them to me/took them from a store or family member/got them some other way. This latter measure of store purchases was restricted to current smokers under age 18 who gave a response other than that they did not try to get cigarettes in the past 30 days. We also examined current (30-day) alcohol use (any vs none) to determine if trends for smoking and drinking differed.

\section{Analyses}

To compare smoking outcomes in Needham with the 16 comparison communities, we conducted pooled cross-sectional analyses. First, we fit a series of Poisson regression models for each of the two smoking outcomes (current smoking and current purchase of cigarettes in a store) using generalised estimating equations (SAS Proc GENMOD). ${ }^{11}$ The models estimated three parameters: (1) differences in the proportion of youth reporting each outcome at baseline (2006), comparing Needham to the 16 surrounding communities $\left(\beta_{1}\right)$; $(2)$ change in these proportions across consecutive survey years (eg, 2006-2008, 20082010 , and 2010-2012) across all study communities $\left(\beta_{2}\right)$; and (3) whether the change over time differed between Needham and the comparison communities, the main parameter of interest $\left(\beta_{3}\right)$. All models adjusted for two measures of school composition: per cent of students receiving free/reduced cost school lunch (an index of socioeconomic status) and per cent of Caucasian students (an index of racial/ethnic composition), both mean centred. For example, to compare the prevalence of current smoking between 2006 and 2008, we used data for these 2 years only and fit the following model:

$$
\begin{aligned}
\text { Smoking }= & \beta_{0}+\beta_{1} \text { Needham }+\beta_{2} 2008+\beta_{3} 2008 \times \text { Needham } \\
& +\beta_{4}(\% \text { free lunch })+\beta_{5}(\% \text { non }- \text { white })
\end{aligned}
$$

Similar models were fit comparing 2008 with 2010 and 2010 with 2012, with separate models estimated for the prevalence of current cigarette use, current purchase of cigarettes in a store and current alcohol use.

Second, we modelled the prevalence of current smoking, current store purchases of cigarettes and current alcohol use for years 2006-2010 only, with a linear term for study year because, as shown below, models including these years produced a consistent pattern of results. This final model was:

$$
\begin{aligned}
\text { Smoking }= & \beta_{0}+\beta_{1} \text { Needham }+\beta_{2} \text { Study year }+\beta_{3} \text { Study year } \\
& \times \text { Needham }+\beta_{4}(\% \text { free lunch })+\beta_{5}(\% \text { non }- \text { white })
\end{aligned}
$$

where again $\beta_{3}$ is the coefficient of interest reflecting differences in change over time for Needham compared with the 16 comparison communities from 2006 to 2010. This model was fit for current smoking and current alcohol use for various subgroups (gender, race/ethnicity, grade) to examine whether the overall pattern of results was consistent across different student populations.

\section{RESULTS}

\section{Smoking behavior}

Thirty-day smoking prevalence is shown in figure 1A, along with the results of the Poisson regression models that summarise the findings for consecutive survey years. In 2006, current smoking did not differ significantly between Needham and the 16 comparison communities. From 2006 to 2008, current smoking decreased at a greater rate in Needham than in the comparison communities $\left(\beta_{3}=-0.174, \mathrm{p}<0.001\right)$, and again from 2008 to $2010\left(\beta_{3}=-0.278, \mathrm{p}<0.001\right)$. However, from 2010 to 2012 , decreases in current smoking were significantly greater in the comparison communities than in Needham $\left(\beta_{3}=0.143, \mathrm{p}<0.01\right)$.

Results of additional analyses on current smoking restricting data to the time period 2006-2010 are presented in table 1 . These analyses were restricted to the first three surveys because that was the period of time during which the decline in youth smoking was significantly greater in Needham relative to the comparison communities. In 2006, shortly after the minimum purchase age was raised in Needham, the estimated prevalence of 30-day smoking between Needham and the comparison communities did not differ $\left(\beta_{1}=0.062\right.$; ns (non-significant)); the prevalence for all communities decreased significantly with time $\left(\beta_{2}=-0.050 ; \mathrm{p}<0.001\right)$. Most notably, the overall decline in Needham's 30-day smoking prevalence exceeded that of the comparison communities combined $\left(\beta_{3}=-0.108 ; \mathrm{p}<0.001\right)$. This statistically greater decline in Needham was observed for all subgroups (females, males, Caucasian, non-Caucasian, and by student grade), with the exception of ninth grade youth, who reported low levels of smoking.

\section{Cigarette purchases in stores}

From 2006 to 2012, the percentage of youth under age 18 who purchased cigarettes in stores decreased significantly more in Needham (from $18.4 \%$ to $11.6 \%$ ) than in the comparison communities (from $19.4 \%$ to $19.0 \%$; $\mathrm{p}<0.001$ ) (see figure 1B). The findings follow the same general pattern as current smoking: the rate of decline in purchasing cigarettes in Needham relative to the comparison communities was greatest for the period from 2006 to $2008\left(\beta_{3}=-0.667 ; \mathrm{p}<0.001\right)$, lessened for the period from 2008 to $2010\left(\beta_{3}=0.200 ; \mathrm{p}<0.05\right)$, and did not show a significant change from 2010 to $2012\left(\beta_{3}=0.029\right.$; ns). Since the pattern of findings was similar to that of current smoking, we also examined the overall change from 2006 to 2010; the decline in store purchases in Needham over this period was greater than in the comparison communities $\left(\beta_{3}=-0.465\right.$, $\mathrm{p}<0.001)$.

\section{Comparison to alcohol use}

Notably, the findings for current alcohol use were distinct from those for current cigarette smoking: from 2006 to 2012, there was a general decline in the 30-day prevalence of drinking, with no significant differences between Needham and the comparison communities over any of the consecutive survey waves (see figure 1C). Models for the combined years spanning 20062010 also show that there was no significant difference in the 30-day prevalence of drinking in Needham compared with the 16 comparison communities $\left(\beta_{3}=-0.003 ; \mathrm{ns}\right)$ (data not shown). 
Figure 1 Trends in current $(A)$ cigarette smoking, (B) store purchases of cigarettes and (C) alcohol use in Needham vs 16 comparison communities, 2006-2012. * $p<0.05$, ${ }^{* *} p<0.01,{ }^{* *} p<0.001$. †Among current smokers who tried to obtain cigarettes in the past 30 days.

Note: The minimum purchase age was raised to 21 in 2005 . The numbers between time points represent the $\beta$ coefficients from a series of Poisson regression models that estimated the change in use/purchase in Needham relative to the 16 comparison communities over consecutive time periods (2006-2008, 2008-2010, and 2010-2012) controlling for race/ ethnicity and socioeconomic status at the school level.
A

Current Cigarette Smoking

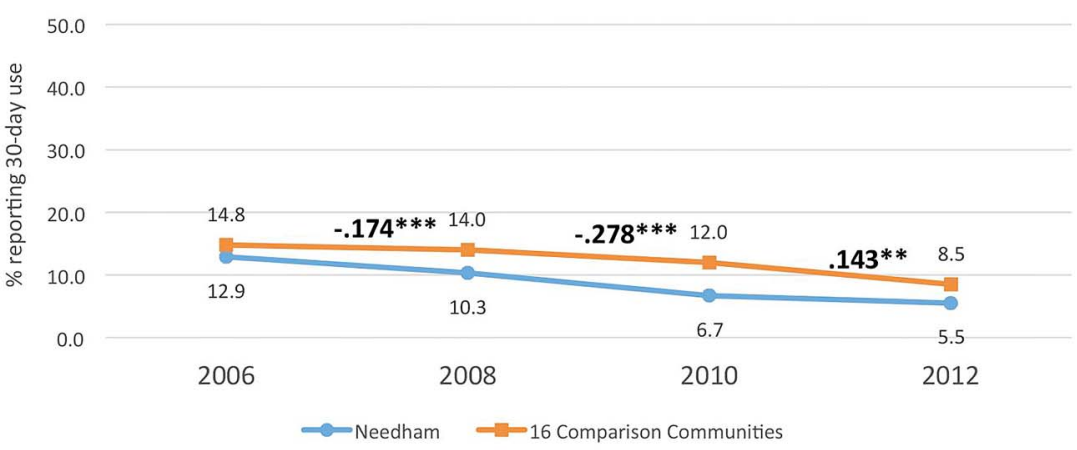

B

Current Store Purchases of Cigarettes†
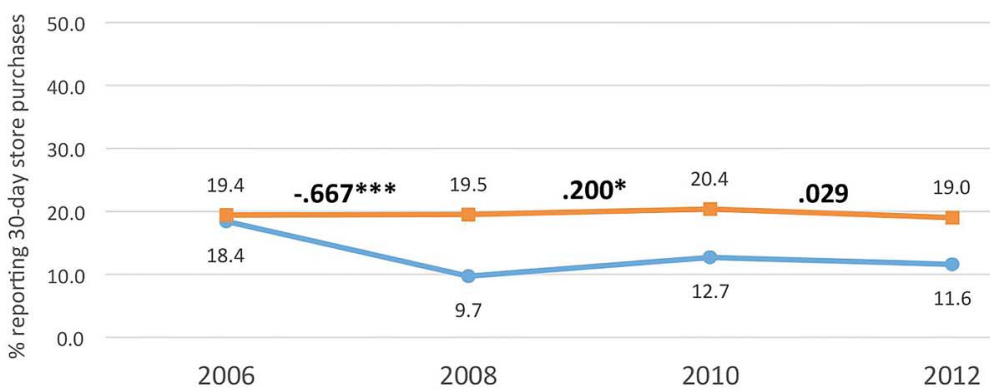

- Needham -16 Comparison Communities

C Current Alcohol Use

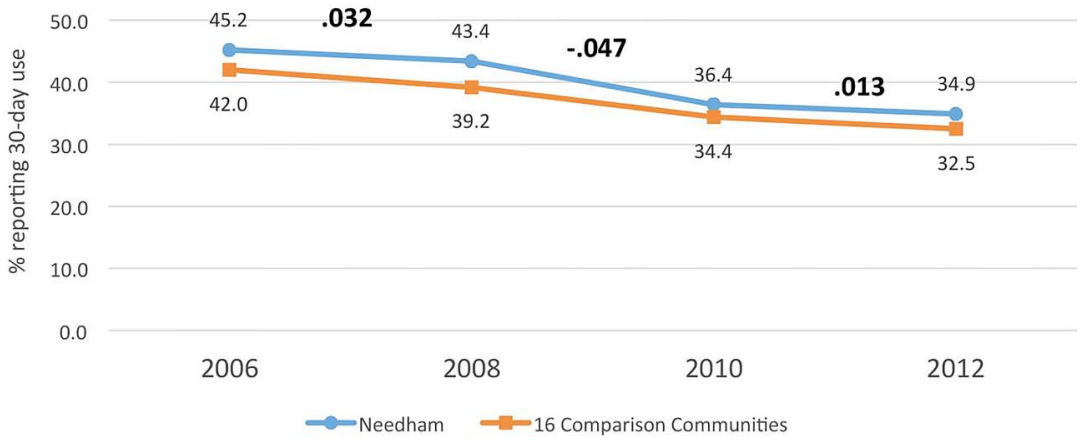

cigarettes. Comparing data from Needham and 16 surrounding communities, we showed a significantly greater decline in current smoking in Needham soon after the minimum purchase age was raised, overall and for males, females, Caucasian and

\section{DISCUSSION}

As more communities are debating whether or not to raise the minimum sales age of tobacco, it is important to examine the effects this policy may have on youth smoking and access to

Table 1 Stratified models predicting 30-day cigarette smoking, Needham versus 16 comparison communities, 2006-2010

\begin{tabular}{|c|c|c|c|c|c|c|c|c|c|}
\hline & \multirow[b]{2}{*}{ Total } & \multicolumn{2}{|l|}{ Gender } & \multicolumn{2}{|c|}{ Race/ethnicity } & \multicolumn{4}{|l|}{ Grade } \\
\hline & & Females & Males & Caucasian & Non-Caucasian & 9th & 10th & 11th & 12th \\
\hline \multicolumn{10}{|l|}{ Cigarette smoking } \\
\hline Intercept & $-1.922^{* * *}$ & $-2.032^{* * *}$ & $-1.831^{*}$ & $-1.947^{* * *}$ & $-1.794^{* * *}$ & $-2.551 * * *$ & $-2.001 * * *$ & $-1.809 * * *$ & $-1.546^{* * *}$ \\
\hline$\beta_{1}$-target community (Needham) & 0.062 & $0.258 * * *$ & -0.101 & $0.089 *$ & 0.068 & 0.046 & $-0.162^{*}$ & 0.022 & $0.270 * * *$ \\
\hline$\beta_{2}$-time & $-0.050 * * *$ & $-0.084^{* * *}$ & -0.025 & $-0.058^{* * *}$ & $-0.034^{*}$ & $-0.082^{*}$ & $-0.086^{* * *}$ & $-0.044^{* *}$ & -0.023 \\
\hline$\beta_{3}$-timextarget community & $-0.108^{* * *}$ & $-0.214^{* * *}$ & $-0.038^{*}$ & $-0.129 * * *$ & $-0.074^{* *}$ & -0.028 & $-0.059 * *$ & $-0.134^{* * *}$ & $-0.192^{* * *}$ \\
\hline Percentage of free/reduced lunch & $0.026 * * *$ & $0.032 * * *$ & $0.021 * * *$ & $0.030 * * *$ & $0.019 * * *$ & $0.044^{* * *}$ & $0.029 * * *$ & $0.024^{* * *}$ & $0.019^{* * *}$ \\
\hline Percentage of Caucasian & $0.020 * * *$ & $0.026 * * *$ & $0.016^{* * *}$ & $0.021 * * *$ & $0.022 * * *$ & $0.032 * * *$ & $0.019 * * *$ & $0.019 * * *$ & $0.019 * * *$ \\
\hline
\end{tabular}


non-Caucasian youth, and for students in grades 10, 11 and 12 . These trends were significant from 2006 to 2010, but not from 2010 to 2012, suggesting that raising the minimum purchase age may contribute to a greater decline in smoking in the years immediately following its adoption. As the smoking rate decreased in Needham, floor effects might have slowed the rate of decline in the period from 2010 to 2012; however, the smoking rate still declined by $18 \%$ in that final period.

In addition to lower levels of smoking, Needham youth also reported a significantly greater decline in purchasing cigarettes from stores in the years immediately following the legislation. This was true despite the fact that the youth population in Needham is very mobile, and closely neighbouring suburban communities maintained a minimum sales age of 18 throughout the study period. The decline in smoking in Needham may have been even more pronounced if surrounding communities had also increased the tobacco sales age to 21, as this would have further limited access. Youth who purchase cigarettes are more likely to supply cigarettes to other youth, ${ }^{12}{ }^{13}$ and these social sources of tobacco have become more common as commercial restrictions have increased. ${ }^{5}$ Our findings suggest that by successfully reducing commercial availability of cigarettes to Needham youth, there was a decrease in underage purchases, as well as a potential disruption of the social availability of cigarettes to other youth, resulting in less smoking.

Also notable was the fact that alcohol use did not decline significantly more in Needham relative to the comparison communities during any portion of the study period. This indicates that the observed pattern of change appears to be specific to cigarette smoking and not due to a broader decline in substance use or reporting patterns.

Enforcement may partially explain the apparent success of raising the minimum tobacco sales age in Needham. Effective enforcement is important in the success of laws designed to prevent tobacco sales to minors. ${ }^{14}$ In 2008, more than 18000 compliance checks for cigarette sales to adolescents under the age of 18 were conducted in Massachusetts towns with statefunded tobacco control programmes, with an illegal sales rate of 8.3\%. In Needham, 57 compliance checks were conducted, with zero illegal sales to those under the age of 18 occurring. ${ }^{15}$ Increasing the tobacco sales age to 21 may have made it less likely that adolescents under the age of 18 would have been sold tobacco.

Several limitations are worth noting. First, this study was not initially designed to evaluate the minimum sales age legislation; the 2006 survey was administered more than 1 year after the legislation was adopted in April of 2005; therefore, there is no baseline measure of youth smoking. It also does not take into account the fact that the minimum sales age in Needham was increased in phases: it was first raised from 18 to 19 in April of 2003, then to 20 in April of 2004, and finally to 21 in April of 2005. Data reported from the Youth Risk Behavior Survey conducted in Needham (Needham Youth Risk Behavior Survey, unpublished raw data, 2001-2005) and the state of Massachusetts $^{16}$ in 2001, 2003 and 2005 provide some information on trends prior to the current study. In Needham, current smoking was similar in 2001 (21\%) and 2003 (20\%), and then dropped to $15 \%$ in 2005 , corresponding with the first two increases in the minimum sales age. During the same time period, smoking decreased in Massachusetts from 26\% to 21\% during 2001-2003, and then was stable at $21 \%$ in 2005. This suggests that the greater decline in smoking in Needham in this study may be a continuation of a trend that began earlier, possibly around the time when the minimum sales age was initially raised. Second, Needham also passed a law in 2009 prohibiting tobacco sales in pharmacies, which may have contributed to the smoking decline after the 2008 survey. With the exception of one other study community that banned pharmacy sales in 2011, neither Needham nor any of the comparison communities adopted any of the Massachusetts Tobacco Control Program's five priority prevention policies during the study period (banning pharmacy sales, capping tobacco licenses, regulating single cigar purchases, banning flavoured tobacco sales and regulating electronic cigarette purchases) (M Paskowky, Director of Surveillance and Evaluation, Massachusetts Tobacco Cessation and Prevention Program, Massachusetts Department of Public Health, personal communication, 6 November 2014). This study did not account for non-policy-related programmes in Needham or the other communities. Finally, this study analysed the use of cigarettes only and did not examine the use of other tobacco products.

Despite these limitations, this study shows promising results on the potential impact of raising the minimum sales age of tobacco. Further, raising the minimum age is relatively simple to implement given the existing mechanisms to restrict tobacco purchases and conduct compliance checks. ${ }^{17}$ As this approach is considered in more and more localities, our findings provide strong evidence of its potential to save lives by preventing youth access, initiation and ultimately addiction.

\section{What this paper adds}

- An increasing number of communities are implementing policies to raise the minimum sales age of tobacco to 21 , but there is little direct evidence regarding whether this strategy is effective in reducing youth smoking.

- We have demonstrated that, after raising the minimum sales age in Needham, Massachusetts, smoking and cigarette purchases declined significantly more in Needham relative to 16 comparison communities.

- These findings are valuable to localities that are considering raising the minimum age, in showing that this approach has the potential to reduce youth access and initiation, with potentially life-saving benefits.

Acknowledgements The authors express their gratitude to the MetroWest Health Foundation, specifically Martin Cohen, CEO/president, and Rebecca Donham, senior program officer, for funding the MetroWest Adolescent Health Survey (MWAHS) initiative and encouraging Education Development Center's (EDC) efforts to conduct this analysis. They thank the Needham Public Schools and Needham Health Department for permitting public use of the Needham data and assisting with documentation of local substance use prevention activities. They also acknowledge Dr Robert Crane for encouraging them to engage in this analysis, and Professor George Papandanatos and Dr Michelle Rogers for biostatistical and programming guidance. Finally, they thank the MWAHS team at EDC, including Erin Smith, Robert Coulter and Olivia Alford, and the many school administrators and staff who worked to ensure the successful administration of the MWAHS since 2006.

Contributors All authors participated in the study conceptualisation. SKS originated the study, oversaw data collection and drafted portions of the manuscript. SLB and KD oversaw the analysis and contributed substantially to the manuscript writing. JPW contributed to the conceptualisation and manuscript editing. LO contributed substantially to the study design and manuscript writing.

Funding The MetroWest Adolescent Health Survey data collection was funded by the MetroWest Health Foundation in Framingham, Massachusetts, USA (grant numbers P150, P182, P192 and P225).

Competing interests None declared.

Ethics approval The study was approved in all years by the Institutional Review Board at Education Development Center, Inc, Waltham, Massachusetts, USA. 
Provenance and peer review Not commissioned; externally peer reviewed.

\section{REFERENCES}

1 Mickle T. More cities raise tobacco age to 21: industry stands to lose $\$ 2$ billion of sales, near term, if change is made nationally. Wall Street Journal 28 Oct 2014. http://online.wsj.com/articles/more-cities-raise-tobacco-age-to-21-1414526579 (accessed 2 Dec 2014).

2 Kann L, Kinchen S, Shanklin SL, et al., Centers for Disease Control and Prevention (CDC). Youth risk behavior surveillance-United States, 2013. MMWR Surveill Summ 2014;63(Suppl 4):1-168.

3 Taioli E, Wynder EL. Effect of the age at which smoking begins on frequency of smoking in adulthood. N Engl J Med 1991;325:968-9.

4 US Department of Health and Human Services. The health consequences of smoking - 50 years of progress: a report of the Surgeon General. Atlanta, GA: US Department of Health and Human Services, Centers for Disease Control and Prevention, National Center for Chronic Disease Prevention and Health Promotion, Office on Smoking and Health, 2014.

5 Difranza JR, Coleman M. Sources of tobacco for youths in communities with strong enforcement of youth access laws. Tob Control 2001;10:323-8.

6 Johnston LD, O'Malley PM, Miech RA, et al. Monitoring the future national results on adolescent drug use: overview of key findings, 2013. Ann Arbor, MI: Institute for Social Research, the University of Michigan, 2014.

7 Institute of Medicine. Public health implications of raising the minimum age of legal access to tobacco products. Washington DC: The National Academies Press, 2015.
8 Ahmad S, Billimek J. Limiting youth access to tobacco: comparing the long-term health impacts of increasing cigarette excise taxes and raising the legal smoking age to 21 in the United States. Health Policy 2007;80:378-91.

9 Winickoff JP, McMillen R, Tanski S, et al. Public support for raising the age of sale for tobacco to 21 in the United States. Tob Control 2016;25:284-8.

10 Centers for Disease Control and Prevention. 2013 Youth Risk Behavior Survey. http://www.cdc.gov/healthyyouth/yrbs/pdf/questionnaire/2013_hs_questionnaire.pdf (accessed 18 Nov 2014).

11 SAS Institute Inc. SAS/STAT® 13.1 User's Guide. Cary, NC: SAS Institute Inc, 2013.

12 Wolfson M, Forster JL, Claxton AJ, et al. Adolescent smokers' provision of tobacco to other adolescents. Am J Public Health 1997;87:649-51.

13 Pokorny SB, Jason LA, Schoeny ME. Youth supplying tobacco to other minors: evaluating individual and town-level correlates. J Youth Adolesc 2006;35:705-15.

14 Difranza JR. Which interventions against the sale of tobacco to minors can be expected to reduce smoking? Tob Control 2012;21:436-42.

15 Massachusetts Department of Public Health Tobacco Control Program. Annual Report on Youth Access to Tobacco. (FY 2008). http://www.mass.gov/eohhs/docs/ dph/tobacco-control/annual-report-2008.pdf (accessed 1 Dec 2014).

16 Massachusetts Department of Elementary and Secondary Education, Massachusetts Department of Public Health. Health and risk behaviors of Massachusetts youth, 2007: the report. 2008. http://www.doe.mass.edu/cnp/hprograms/yrbs/2007YRBS. pdf (accessed 10 Apr 2015).

17 Winickoff JP, Gottlieb M, Mello MM. Tobacco 21-an idea whose time has come. N Engl J Med 2014;370:295-7. 